\title{
THE BODY OF HIERARCHY: HAND GESTURES ON CLASSIC MAYA CERAMICS AND THEIR SOCIAL SIGNIFICANCE
}

\author{
Anna Bishop $\mathbb{1}^{\mathrm{a}}$ and Erica A. Cartmill ${ }^{\mathrm{b}}$ \\ aDepartment of Archaeology, University of California Los Angeles, A210 Fowler Building, 308 Charles E. Young Drive, North UCLA, \\ Los Angeles, California 90095 \\ bepartment of Anthropology, University of California Los Angeles, 375 Portola Plaza, 341 Haines Hall UCLA, Los Angeles, \\ California 90095
}

\begin{abstract}
Classic Maya (A.D. 250-900) art is filled with expressive figures in a variety of highly stylized poses and postures. These poses are so specific that they appear to be intentionally communicative, yet their meanings remain elusive. A few studies have scratched the surface of this issue, suggesting that a correlation exists between body language and social roles in Maya art. The present study examines whether one type of body language (hand gestures) in Classic Maya art represents and reflects elements of social structure. This analysis uses a coding approach derived from studies of hand gesture in conversation to apply an interactional approach to a static medium, thereby broadening the methods used to analyze gesture in ancient art. Statistics are used to evaluate patterns of gesture use in palace scenes across 289 figures on 94 different vases, with results indicating that the form and angling of gestures are related to social hierarchy. Furthermore, this study considers not just the individual status of each figure, but the interaction between figures. The results not only shed light on how gesture was depicted in Maya art, but also demonstrate how figural representation reflects social structure.
\end{abstract}

\section{INTRODUCTION}

Body language is a form of communication that permeates everything we do. Many of the gestures we use reflect the beliefs, practices, and metaphors of the societies we inhabit (Kita 2009; Quinn 2008), yet despite its cultural ubiquity, archaeologists know little about the body language and gestures of past civilizations. Body language in art has a history of subtly storing detailed information for its targeted audience, a strategy well-known from the mudras of East Asia, which were used in Buddhist and Hindu ritual and iconography to identify divinities and seal rites (Todaro 1985). Gesture is a unique form of communication independent of text and speech, with the capacity to express not only information about the gesturer's intended meaning, but also about their identity and relation to others. For example, beckoning someone closer with the palm facedown indicates both something about the communicative intent (beckoning), but also something about the gesturer (that she is probably from a country like Italy where beckoning is typically done palm-down). It could also tell you something about the status of the individual (e.g., that they have the power to call others to their side, at least in the context of the gesture). The archaeology of New World complex societies is replete with imagery of individuals, yet limited in text, highlighting the necessity for an anthropological study of body language. The Maya are an ideal case study due to the rich repertoire of posed figures that are

E-mail correspondence to: Abbishop@UCLA.edu found in Classic period (A.D. 250-900) art and because the aesthetic and ritual practices are consistent with a communicative, aesthetic, and possibly codified use of the body in Maya culture.

In order to approach a topic as broad and complex as gesture in an ancient civilization, we employ Bourdieu's concept of habitus as a theoretical framework for understanding how gesture relates to culture. In brief, habitus is the internalization and repetition of social structures and daily norms by the individual (Bourdieu 1977, 1990). Each person's habitus is based on his or her individual experiences, however it is argued that those of the same class (within the same society) will have largely similar habitus because they share daily experiences and defining social structures (Throop and Murphy 2002). Every day a person expresses their habitus through their words, actions, and interactions, and by expressing it they perpetuate it. In this way habitus is reconstructed as it is repeated.

Habitus is conveyed without conscious intention and is so ingrained that it is mistaken for a natural trait (Bourdieu 1977, 1990). One way habitus manifests is through "bodily hexis," which is when habitus is physically performed or embodied (Bourdieu 1977:93-94). Similar to Mauss' (1973) concept of body techniques, "bodily hexis" refers to the movements, postures, and gestures that the body makes that are socially learned conventions (Bourdieu 1977, 1990; Throop and Murphy 2002). We argue that habitus and bodily hexis can be applied to the study of ancient art to gain insight into past social structures and their governing rules of interaction. These concepts are used here to guide our study of the postures and manual gestures depicted in Maya art. 


\section{GESTURE ANALYSIS IN ANTHROPOLOGY AND ARCHAEOLOGY}

Today gesture is investigated in linguistic and ethnographic studies of living people to gain insight into shared cultural values or ideologies. For example, Le Guen and Pool Balam's study (2012) of gestures among the Yucatec Maya proposes that the modern Maya conception of temporality can be understood through an examination of the gestures speakers use when discussing time. They found that Maya speakers use cyclical gestures when talking about time, and lack timeline gestures representing a linear plane on which events occur sequentially (common in Western countries). The study supports previous research on modern Maya views of chronometry (Bricker 1981), by showing that cyclical schemas were embodied in speakers' spontaneous gesturing. Maya temporality is essential to other core cultural beliefs that link time and the calendar to ancestor worship and social memory (McAnany 1995; Tedlock 1992). The ways in which people interpret acts of gesturing is also used in linguistic anthropology to learn about practices of socialization and ideologies of communication within a society. Haviland's (1998) study of Zinacantan infant gestures provides an excellent example of this approach, using adult interpretations of infant movements to show that spoken language and gesture are not considered separate systems to Zinacantecos, and are employed in tandem to socialize infants from a very early stage. Thus, the study of gesture is validated in the ethnographic present as a critical point of departure for investigating and explaining wider ideologies within a society.

A study of gesture in early civilizations also provides a means to explore past cultural concepts and beliefs. Applications of gesture in archaeology are uncommon and have made use of varied methods, ranging from art historical assessment of artistic compositions and aesthetics (Benson 1973; McNiven 1982; Miller 1981; Troike 1982), to analysis of texts describing gesture within narratives, performances, and orations (Bremmer 1991; Graf 1991; Olko 2014), to phenomenological approaches that trace the kinesthetic movements that occur with a chaîne opératoire or the use of certain objects (Matthews 2004).

\section{Art History}

McNiven's (2007) research on Greek vase painting is an exemplary study of gesture in archaeology. McNiven found that body posture and gesture were displayed differently in masculine versus feminine forms as well as for mature versus juvenile figures. For example, in Athenian vase painting, only adult males are depicted shaking hands, never children (McNiven 2007). McNiven interprets this as a sign that hand shaking is associated with maturity and adulthood, which adds greater meaning to its use in certain contexts, especially in coming of age narratives. On Onesimo's cup tondo in the Louvre Museum, the young protagonist Theseus arrives at the palace of Poseidon after receiving the title as heir to the throne of Athens (McNiven 2007:97). In this instance, despite his young appearance, he is greeted with a handshake by Amphitrite, suggesting this is a moment of transition into manhood (McNiven 2007).

McNiven's approach to the archaeological record is art historically based and searches for contextual elements that consistently occur in each instance of a gesture. Similar methods have been used by Troike (1982) in the Mixtec codices to identify gestures of request and acceptance, and by Miller (1983) to evaluate the meaning of so-called "submission gestures" in Maya sculpture. In both studies, the authors record the appearance of different gestures from a large corpus of art, and determine meaning based on the context in which the gestures appear. Scholars have since employed a similar analytic approach with the introduction of inferential statistics, such as Palka's (2002) work on the use of right-handed versus left-handed gestures in Maya iconography, and Ancona-Ha and colleague's (2000) analysis of 16 different hand and arm gestures on Classic Maya vases.

\section{Text and Language}

Other studies lean on textual sources and language to interpret gesture, limiting the use of iconography to complement interpretations. This approach is common in Old World studies where a wide array of texts survive. One example by Bremmer (1991) scrutinizes passages from the chronicles of Homer, the plays of Aristophanes, and the dialogues of Plato along with early Greek sculpture to illuminate how the Greeks perceived different ways of walking, standing, and sitting. Similarly, Graf (1991) uses stage directions in Roman plays and instructions from Quintilian's textbook on public speaking to determine the social connotations that Romans tied to different movements, with reference to other sources such as Greek vases.

In New World studies, Olko's (2014) research on pre- and post-Conquest gestures among the Nahua investigates postural practices and how they changed in response to European contact, in particular how certain postures were appropriated and applied to Christian rituals as a tool in the Christianization of the indigenous people. Olko uses a mix of post-Conquest codices illustrated by the Nahua, early ethnohistorical accounts written by the Spanish, Colonial Nahuatl dictionaries, and colonial legal documents to inform her interpretations of body language. Her research reveals how gesture was used as a tool in situations of contact and integration, and demonstrates the importance of gesture to the study of history.

\section{A New Method}

Despite the insights gesture can provide to the interpretation of past civilizations, the number of such studies is surprisingly low. One of the goals of the present research was to develop a methodology for investigating gesture in archaeology that relies on the statistical analysis of gesture in art as it relates to social context. This approach revealed latent trends that were not obvious to the naked eye but that emerged through comparison across hundreds of works of art. Techniques used in the study of conversation were also included within the statistical analysis to take this research beyond the assessment of individual figures, to examine interactions between figures. Research on gesture in Maya art has so far focused on individual figures and the gestures they produce (Ancona-Ha et al. 2000; Miller 1981; Palka 2002). Gesture is used, however, for interactions between people, and is shaped by the interlocutor as well as the gesturer. The research here considers both parties involved in an interaction and asks how gesture reflects the speaker's engagement with his/her interlocutor.

\section{Goals and Data for Present Study}

The current study is concerned with the use of gestures in social interaction and their significance. Our principal goal is to provide quantitative assessment of the argument that hand gestures in 
Maya art were not chosen at random, but display predictable patterns, governed by an underlying order of logic or meaning, as has been previously suggested by several studies on the topic (Ancona-Ha et al. 2000; Palka 2002). Furthermore, this research aims to identify the relationship between gesture and the social structures that regulate the body and social interactions in Maya culture. Etiquette and rules of comportment would have resonated through all aspects of courtly life, and been paramount to the members of this formal setting. As Houston and Inomata (2009: 188) explain: "those who overlooked or failed to understand codes, or even the high language of court, would soon be exposed as buffoonish pretenders and excluded from royal society." Given Bourdieu's argument that habitus is heavily determined by class and expressed by gesture in the form of bodily hexis, it follows that status and class will be marked by differences in gesture. This is particularly true of representations of status and class, which rely on stereotyped forms or shared schemas to convey meaning. Past studies have shown that class and social identity are illustrated through the clothing and absolute placement of figures in Maya art (Jackson 2013; Parmington 2003). We demonstrate that these distinctions are also visible in the gestures and body language of depicted figures, and consider what these depictions of gesture tell us about the underlying structures that governed class and interaction in Classic Maya society. The analysis here focuses exclusively on scenes in a palace context, because this is where social differentiation and status is likely to be most pronounced, and because social and conversational interaction is common in Maya court scenes.

We focused on hand gestures because they are very prominent in ancient Maya visual culture. Hands appear in over 40 Maya glyphs, most obviously in the symbol for hand, but also in glyphs that portray mimetic gestures, such as scattering (chok; Figure 1a), or general hand-associated actions such as striking (jatz'; Figure 1b), receiving (ch'am; Figure 1c), and presenting ( $k^{\prime} a l$; Figure 1d; Boot 2003; Palka 2014; Zender 2004). Furthermore, hands and feet are illustrated in great detail in Maya art (often accompanied with fingernails, knuckles, and heels) and are of the few elements that sometimes possess three-dimensional qualities, suggesting that artists devoted great attention and thought to their portrayal. Hands also make up some of the earliest cave art in the Maya region. Hand prints as well as hand outlines can be found in caves across Mexico and Guatemala, and occasionally combine to create expressive images and elaborate animals in a shadowpuppet style (Figure 2; Strecker 2013). The extensive use of hands in Maya visual culture suggests that they were aesthetically significant to artists and meaningful to audiences.

The focus here is on hand gestures on Late Classic Maya polychrome vessels, an artistic medium for the elite, but less formal in nature than monumental art or stone sculpture. We coded contextual elements and gestures, analyzing a corpus of 146 vases for statistical trends in the forms, contexts, and interactive elements of depicted gesture. Our results corroborate current understandings about Maya codes of deference using the way the Maya associated gestures with rank and status, and based on their expectations for how individuals of varying status should accommodate their interlocutors.

While the polychrome vessels of the Classic Maya are covered in intricate and elaborate renderings of people conversing, dancing, and negotiating various social scenarios, these representations of Maya life cannot be taken as veridical snapshots of life for the Classic Maya. Art, although sometimes realistic, is the world drawn through the biased lens of the artist and viewed through the subjective lens of the audience. It is important, therefore, when interpreting art to keep in mind the perspectives of both the artist and the intended audience. The vessels examined in this study are part of an elite complex that was designed for the Maya nobility and displayed in palace contexts, often during ceremonies where they were viewed by the members of the court and foreign dignitaries. Although the scenes and gestures painted on these vessels cannot be interpreted as transparent depictions of real life, the fact that the vessels were publicly displayed in such elite and proper contexts allows us to consider these works of art through the concept of decorum. Baines (1990:20) best describes decorum as a "set of rules and practices defining what may be represented pictorially...in which context and in what form." This refers to the social rules and expectations that govern how people are depicted in a scene, such as what they wear, how they act, and where they appear. These rules reflect what is considered appropriate and decent in society, otherwise the image would be offensive to social values. It is important to remember, however, that decorum reflects an idealized enactment of proper conduct, not how people actually act. Studies of medieval courtly gestures using early texts emphasize that historical sources cannot be taken as genuine records of body language, but rather as evidence of the significance of gesture in palace codes of conduct (Depreux 2009; Schmitt 1991). This same principle applies to depictions of gesture in art.

Because Classic Maya vessels were displayed in such a prominent setting, it can be expected that the scenes on them would follow the expected rules of conduct in Maya society. Therefore, while the gestures on these vessels may not reflect reality, they do most likely reflect social expectations for bodily communication and ideologies of comportment in each given context.

\section{PROLEGOMENA TO THE STUDY OF MAYA CERAMICS}

The polychrome ceramic vessels studied here are prestige items of high quality, painted by artists of significant skill. The scribes of the Maya held a unique place in society that suggests they were of high status. Workshops attached to elite residences (Just 2012; Reents-Budet 1994, 1998), artist signatures with royal lineage statements (Coe and Kerr 1997; Stuart 1989), and iconography showing scribes in close consort with kings (Coe and Kerr 1997:94) all suggest that the manufacturers of these prestige wares were also members of the elite themselves. As associates of the royal entourage, scribes came from a niche section of society with first-hand knowledge of social etiquette, politics, and restricted rituals. Such a background would make artists uniquely qualified to illustrate rituals and courtly life.

Once produced, prestige vessels served a variety of needs throughout their lifetime. The vessels were gifted between elites of different polities to establish amicable relationships and cement political bonds, as evidenced by vessels found outside their region of origin, in the tombs of foreign rulers (Reents-Budet 1994; Reents-Budet et al. 2010; Taschek and Ball 1992). Usewear patterns on the ceramics indicate that these items were used as functional serving wares. Furthermore, rim texts and chemical analysis confirm that these vessels were often used to hold maize and cacao refreshments (Houston et al. 1989; Reents-Budet 1994). Iconographic evidence indicates that the objects were used to serve food during ritual feasts, thus mixing functional and ceremonial use (Figure 3). In this setting, the vessels would have been 


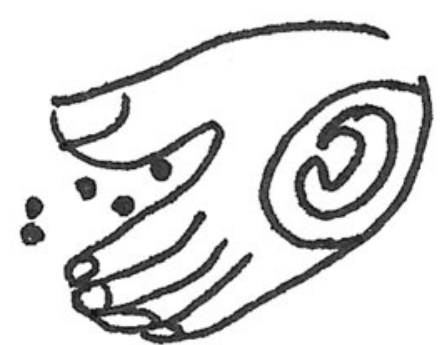

(a)

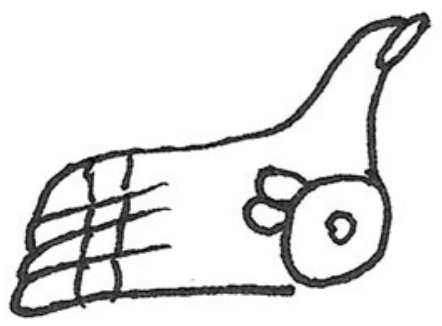

(c)

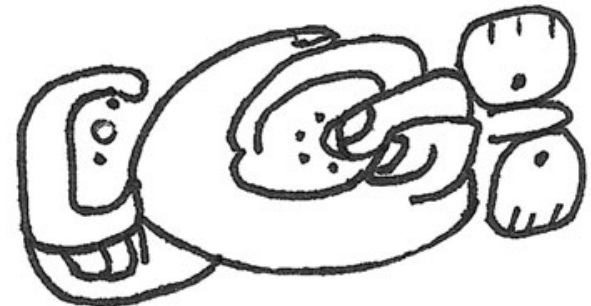

(b)

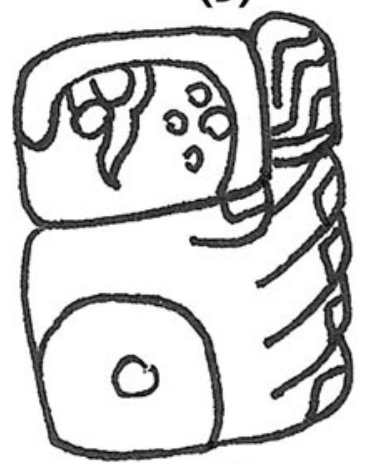

(d)

Figure 1. Examples of Maya glyphs depicting hands. (a) Chok glyph. After Boot (2003:3). (b) Jatz' glyph. After Zender (2004:Figure 6). (c) Ch'am glyph. After Boot (2003:3). (d) K'al glyph. After Boot (2003:8). All drawings by Bishop.

viewed by a private audience of individuals in the court and foreign dignitaries of competing courts, restricting their exposure to a highly educated and socially regulated group (Jackson 2009; Reents-Budet 1994, 1998).

\section{CERAMIC MATERIALS, ICONOGRAPHY, AND STYLES}

The ceramics used in this study come from Kerr's (1999) online Maya Vase Database, which includes major museum and private collections. The polychromes chosen are of the Ik' and Codex styles from the central and northern Peten regions of Guatemala, respectively, and a mix of other Late Classic vessels of unidentified lowland styles. These traditions heavily feature palace scenes, so they are particularly well suited to a study of elite interaction. The Ik' style originates from Motul de San Jose and its surrounding subsidiaries between A.D. 758-850, with a little over 38 known examples (Just 2012; Reents-Budet 1994). These vessels depict court scenes of the typical events in the life of a king, such as the acceptance of tribute, the performance of rituals, and the reception of foreign dignitaries (Figure 4). Some ceramics feature specific historical figures that are either named with a glyph caption or are depicted in a unique way, such as in the case of the "Fat Cacique" (Kerr 1989). While these vessels depict figures in a variety of actions, they are all set in a palace background, and scenes are fairly standardized in their layout. It is clear from their content that these vessels were designed to showcase the activities of the Ik' court and its rulers.

In contrast to the Ik' style, the Codex style has a much larger corpus. This is in part due to the large production area of codex vessels, which are found throughout the northern Peten and originate from at least two different workshop traditions, one at Nakbe and the other south of this, possibly in the area surrounding El
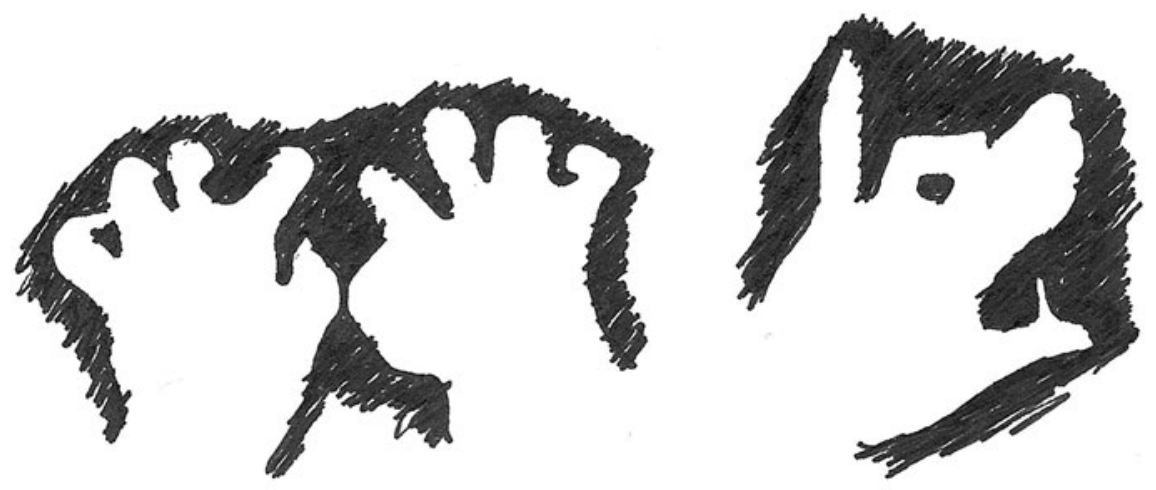

Figure 2. Hand outlines at Acum cave. Drawing by Bishop after Strecker (2013:Figures 6 and 12). 


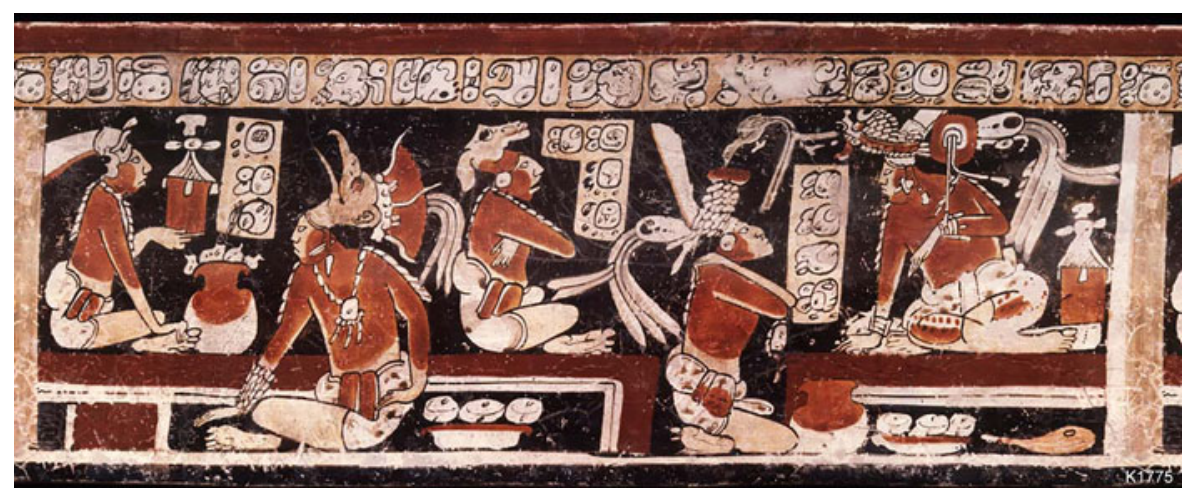

Figure 3. Vase depicting serving vessels in use (Kerr 1999:Kerr No. K1775). Photograph by Justin Kerr.

Tintal (Reents-Budet et al. 2010). The Codex style typically depicts mythical scenes in which the various gods of the pantheon interact with one another, often in an organization similar to the Ik' style, representing courts of the supernatural world (Figure 5; Robicsek and Hales 1981). There are also multiple examples of narrative scenes in this style that have a recurring organization and depiction of characters that are clearly standardized. While the exact subject of each vessel may vary, all depict gods and supernatural beings exclusively. Thus, while the style is freeform in its organization and variety of content, the overall theme of the vessels is strictly mythical.

Finally, a number of vessels were recorded that do not depict a single specific regional style but reflect the general stylistic characteristics of Late Classic lowland Maya ceramics. The objects chosen depict palace scenes, typically also of earthly kings receiving visitors and tribute surrounded by their circle of courtiers and personal attendants. The variety of styles in this group broadens the scope of this study by looking for trends in ceramics across a diverse mixture of sites, outside of the two singular polities above.

\section{METHODOLOGY}

While a definition of gesture that encompasses all possible manifestations is elusive, gesture researchers typically consider gesture to be a deliberate and intentional action, distinguished from more "natural" movements and body positions (Kendon 2004). When gesturing, a limb is "lifted away from the body and later returned to the...position from which it started" (Kendon 2004:12). Following this principle, we define hand gesture as the active posing and positioning of the hand, where the arms and/or fingers are lifted from their natural resting position (i.e., hanging loose at one's sides or resting on a surface). Hands may appear on vessels in a variety of shapes, but not all are lifted and active (i.e., requiring physical effort), and therefore not all should be considered gesture under this definition (see Construction of Gesture Corpus for detailed discussion).

We designed a coding system to categorize gestures based on both the structural features of figures and their hands as well as social features of the interactions depicted in the scene. First, we coded general variables such as style of vessel, type of scene, sex of figure, role of figure, and (if the figure was not a focal figure) figure's distance from the focal figure. Then each figure was coded for gesture form and interaction.

To create the coding categories for each variable of interest, we took a brief sample survey of approximately 50 vases, examining the different ways that each variable presented on vessels. From this subset of the data, we created coding categories for each variable that appropriately captured the unique nature and different possible manifestations we observed. Then we applied this coding system to 146 vases, recording the codes in a Microsoft Access database. The coding process followed a strict set of rules and procedures to assure consistency; however, we also used additional resources to assist in classifying figures and scenes (e.g., to determine the identity and role of figures with glyphic labels). The

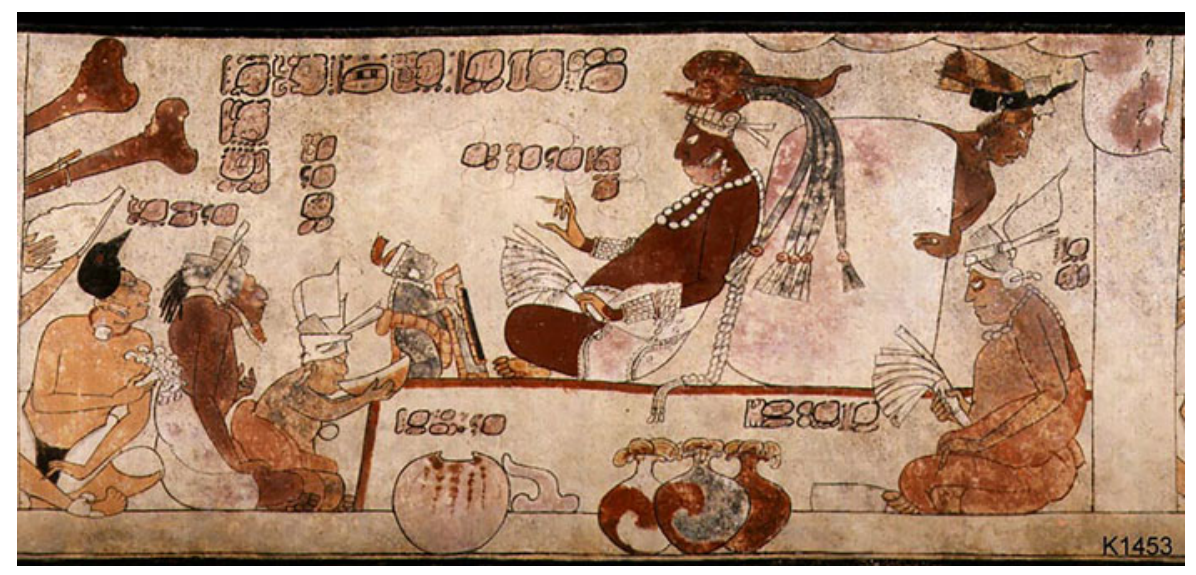

Figure 4. Ik' style vessel (Kerr 1999:Kerr No. K1453). Photograph by Justin Kerr. 


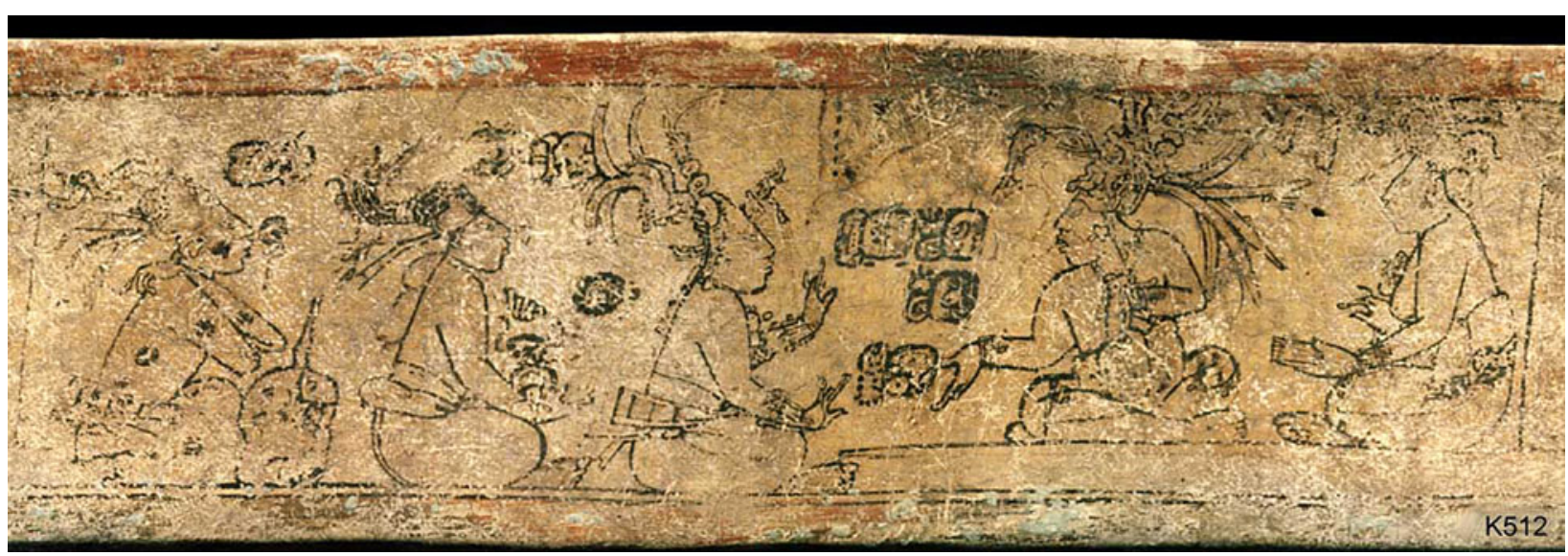

Figure 5. Codex style vessel (Kerr 1999:Kerr No. K512). Photograph by Justin Kerr.

Maya Vase Database, Just's (2012) volume on Ik' Kingdom vase painting, and Coe's (1978) work on Codex-style ceramics were particularly useful references.

We coded a total of 146 vessels, containing 573 figures and 1,146 hands. Some of the data were excluded for particular analyses (this is detailed in the Results: Social Interactions within a Court Context). Variables relating to gesture form and figure context were statistically compared to one another to look for meaningful patterns in gesture use.

\section{Hand Shape}

There are five categories of gesture hand shape roughly corresponding to the number of clusters in which fingers are grouped, each pointing in a different direction (excluding the thumb). Ordered from most articulated (most complex) to least articulated (simplest) the hand shapes we defined were: quadrasected, trisected, bisected, unilateral, and crossed over body. The unilateral gesture was subsequently divided into two categories (open vs. closed) depending on the extension of the fingers.

Of the gestures that appeared regularly, the hand shape with the highest multidirectionality was the trisected gesture. In this gesture, the fingers are separated into three units with the second and fifth fingers extended and the third and fourth fingers bent into the palm, pointing in three directions (Figure 6a). Bisected gestures were those in which the fingers pointed in two different directions, with the fingers grouped into units of three and one or two and two (Figure 6b). In the unilateral gesture, all four fingers were in contact and acted as a single unit. The unilateral category was divided into two subcategories based on whether the fingers were extended or flexed towards the palm. In the unilateral closed gesture, all fingers are bent in towards the palm (Figure 6c). In the unilateral open gesture, all fingers are straight and the palm is open (Figure 6d). The unilateral positions are relatively simple in that they are unidirectional and unsegmented. In the crossed over body gesture, hands grip or rest on the arms or shoulders. Fingers are rarely delineated, and this is the simplest illustration of the hand in a gesture. Many variations of crossed arms gestures were identified by Ancona-Ha, Perez de Lara, and Van Stone (Ancona-Ha et al. 2000) in a study that classified gestures on ceramics from the Maya Vase Book series. Of the 16 gestures described by Ancona-Ha et al., five would fall into our crossed over body category (gestures 4-8 in
Ancona-Ha et al. 2000; Figure 6e). Beyond this, we coded some hands as resting on a surface, not readable due to deterioration of the vessel, or not visible if they were not depicted.

There were instances where handshape was somewhat ambiguous due to the way it was painted. In these cases, the coder made a best guess, following the assumption that if an artist intended to depict a particular handshape, he or she would have made the shape as clear as possible for the viewer. This guideline reduced deliberation over faint and undefined brushstrokes when analyzing the fingers on a hand.

\section{Accommodation}

We also coded gesturing figures in terms of their degree of accommodation to their addressee. When one individual wishes to interact with another, he or she will try to achieve a mutual orientation with that person, meaning that both participants are oriented towards the conversation (Goodwin 1981). Gaze is crucial to this because it signals whether both parties are focused on the interaction and can perceive the visual behaviors of the other. To achieve mutual orientation, an individual may vie for another person's attention by adjusting his hand gestures to reach that person's line of sight (Goodwin 1986). It is this act of adjusting one's gestures to attain mutual orientation that we term accommodation.

The person that a figure gestures towards is referred to here as the figure's interlocutor ("addressed recipient" in Goffman [1981]). During the coding process, we coded an interlocutor as either the first individual in line facing the front of the gesturing figure's body, or the focal figure, whichever comes first. In most cases these are the same figure, however occasionally subsidiary figures are positioned behind the focal figure, and attempt to engage with him despite the fact that he faces the other way. In general, most nonfocal figures attempt to engage with the focal, ignoring the other individuals in the scene. A focal figure's interlocutor was deemed to be the first figure in front of the focal that faced him.

We define accommodation as the extent to which a figure adjusts a hand gesture to their interlocutor, by positioning it directly in front of the interlocutor. Accommodation is divided three categories (direct, indirect, and none). We also note two scenarios in which accommodation is not codable (not applicable and unknown). Direct gestures are placed directly in front of the interlocutor (Figure 7a). Indirect gestures are made at either a high or low 

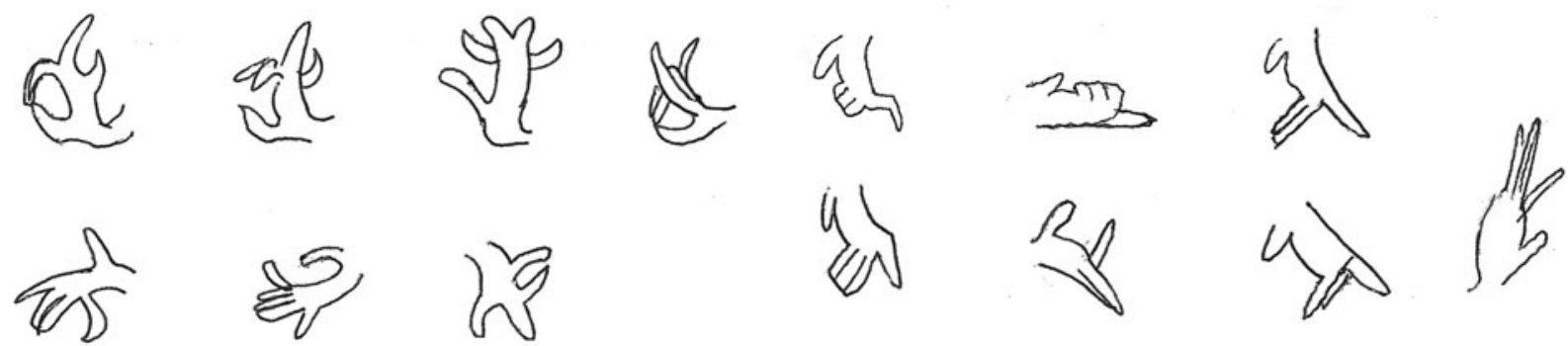

(a)

(b)
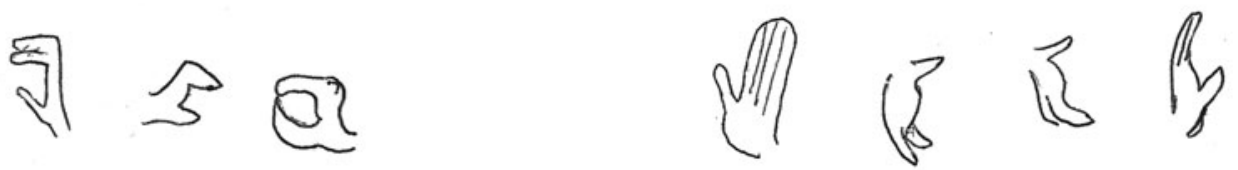

(c)

(d)
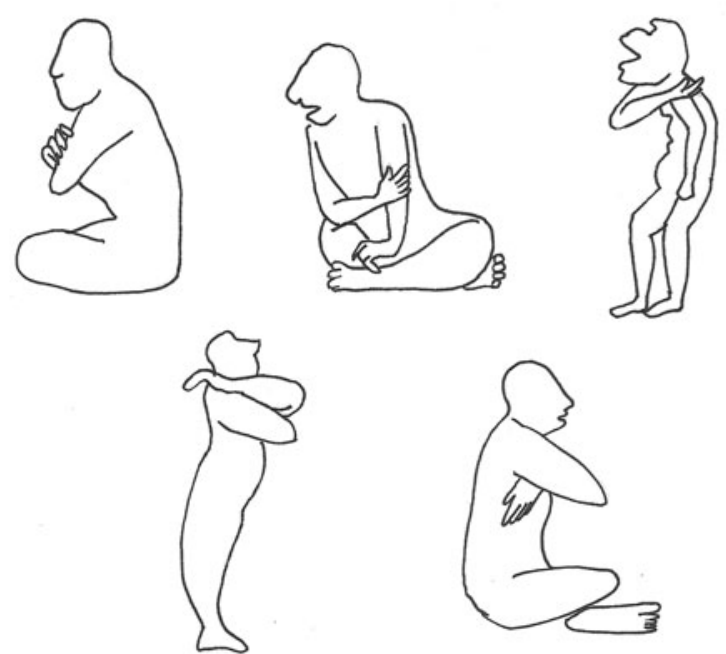

(e)

Figure 6. (a) Variants of trisected gesture. (b) Variants of bisected gesture. (c) Variants of unilateral closed gesture. (d) Variants of unilateral open gesture. (e) Variants of crossed gesture. Drawing by Bishop after Ancona-Ha et al. (2000).

angle in front of the interlocutor, so that the gesture is not positioned within the immediate line of sight of the interlocutor. Accommodation coded as none involves gestures that are either directed away from the interlocutor or fall on a vertical axis running through the gesturing figure (straight up or down). Accommodation is only relevant in instances where a figure gestures to an interlocutor, so figures with no clear interlocutor were categorized as not applicable. Occasionally gestures were too difficult to categorize, in which case they were labeled unknown, but this occurred only twice in the entire dataset.

The position of a direct gestures is different for figures of varying heights, and must be considered from the interlocutor's perspective in terms of his or her line of sight. This concept is modeled in Figures 7a and 7b. Crossed gestures were interpreted as always being direct. Accommodation may potentially demonstrate which figures were expected to adapt themselves to other individuals, and which figures portrayed concern for the visibility of their gestures and movements. These inferences can speak to how characters were expected to interact with one another, particularly in a constructed world of idealized social etiquette.

\section{Position of Figures}

In general, palace scenes depict a common-focused gathering with one focal figure, who is of the highest rank in the frame, and other figures lined up on each side of him on one plane (Figure 5; Kendon 1988:27). The focal is typically located in the center or right side of the artistic frame in palace scenes, while nonfocal figures engage with him by offering tribute, watching him perform rituals, speaking with him, or attending to him. They are all participating in the same "social occasion" (i.e., some type of courtly interaction involving a high-ranking figure), which serves to structure the interaction and provide the context towards which the participants are organized (Goffman 1963:18). 


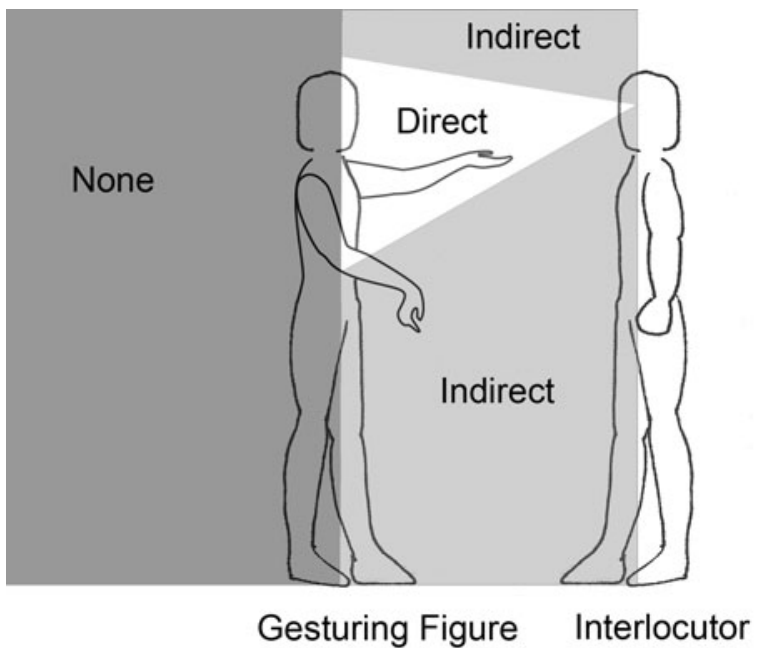

(a)

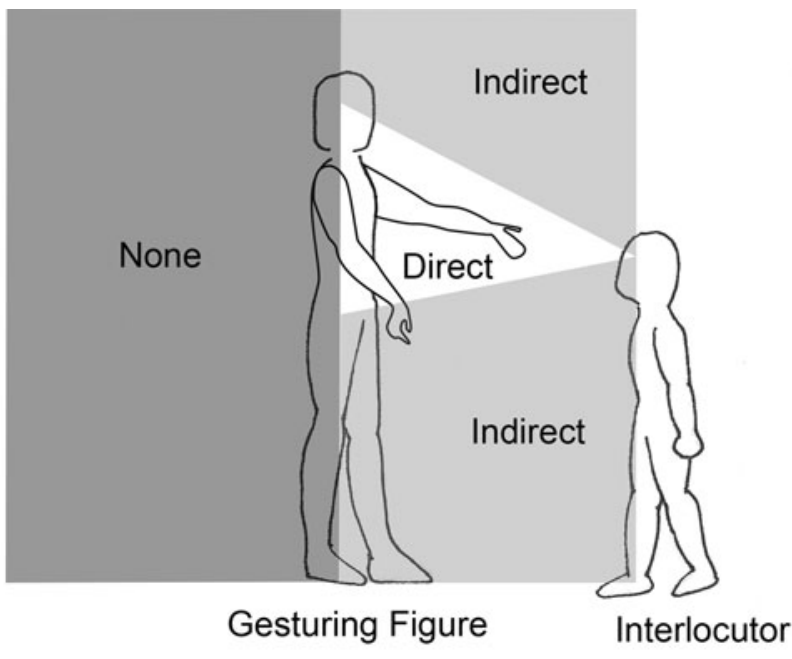

(b)

Figure 7. Forms of accommodation of figures of (a) the same height and (b) differing heights. Images by Bishop.

The focal figure faces and engages with people on his right, however individuals behind him, often servants or advisors, still focus their attention on him, despite the focal figure facing the other way. As in all Maya art, there are exceptions to the standard framework, however these guiding principles characterize most Maya palace scenes. In these palace scenes, all figures share the same space and are part of what Goffman describes as a "gathering" (Goffman 1963:18), because they are in one another's immediate presence. The social significance of figure organization in these scenes has been discussed in detail by other studies, pointing to spatial hierarchies, and physical proximity between individuals as a marker of similar status and exclusive affiliations (Houston 1998; Houston et al. 2006; Jackson 2009; Palka 2002; Reents-Budet 1994, 2000).

We measured each figure's proximity to the focal figure, relative to other figures in the scene. The focal figure was identified as the individual towards which all other characters faced. Each figure was given a position number to categorize how close he was to the focal. Figures that were the first in front or in back of the focal were labeled as proximal, while individuals beyond this were labeled as distal. Characters that were more than one figure away from the focal were grouped into the distal category in order to create a robust sample for comparison, because as the distance from the focal figure increased, the number of examples in our sample decreased.

The proximity of a figure to the focal character is a good measure of rank because, typically, figures closest to the focal are associated with higher status (Ancona-Ha et al. 2000; Jackson 2009). In actual Maya courts, it is probable that only individuals high in the social order consorted closely with the king, therefore figures close to the king in artistic representations of courts most likely held a similar standing (Ancona-Ha et al. 2000; Jackson 2009). This variable is often used in art historical analysis as a measurement of status, and has the advantage of being a fairly objective attribute for coding purposes that can be easily quantified.

\section{Construction of the Gesture Corpus}

The initial dataset consisted of 146 vessels with 1,146 analyzable hands, but not all of the hands on these vessels provided data about the relationship between hand gesture and social standing. To account for this, we excluded several types of images from the final dataset for analysis. Because this study is focused on gestures used in social interaction in Maya courts, all images that did not depict social or conversational interaction within court scenes were excluded.

First, scenes with only one figure were removed, because they did not contain interaction between individuals. This brought the total number of hands assessed down to 1,076. Next, dancing figures were excluded from the analysis because they do not depict daily social or conversational interaction, and may instead represent choreographed movements. Then, figures in narrative scenes were excluded because they did not reflect a palace context. Notably, narrative scenes do not follow the standard compositional format of classic polychrome vessels. Narrative scenes can include multiple focal figures, and there are overlapping foregrounds and backgrounds on which figures overlay one another. This made determining a figure's proximity to the focal figure particularly difficult. These differences made it apparent that narrative scenes are categorically different from palace scenes. After gestures from dance and narrative contexts were removed from the dataset, the remaining records represented 357 figures and 715 hands across 93 vessels.

Finally, we excluded from analysis any hands that were not "actively gesturing." Active gestures were defined as hands that appeared to be engaged in communication: taking on clearly defined shapes or extended towards other figures. This meant we excluded hands that were resting on surfaces as well as those depicted as relaxed at a figure's side. Figure 8 shows examples of the distinction between active and inactive hands. In Figure 8, the Maize God makes a gesture with his right hand that shows accommodation towards his interlocutor. This would be coded as an active gesture. His left hand, however, would be considered inactive because it hangs loosely at his side with no fingers lifted. When inactive gestures were excluded from the data, it reduced our dataset to 408 hands.

Finally, where both the shape and the accommodation of a gesture could not be determined because the vessel's paint was too eroded, the data was excluded. This brought our final total to 


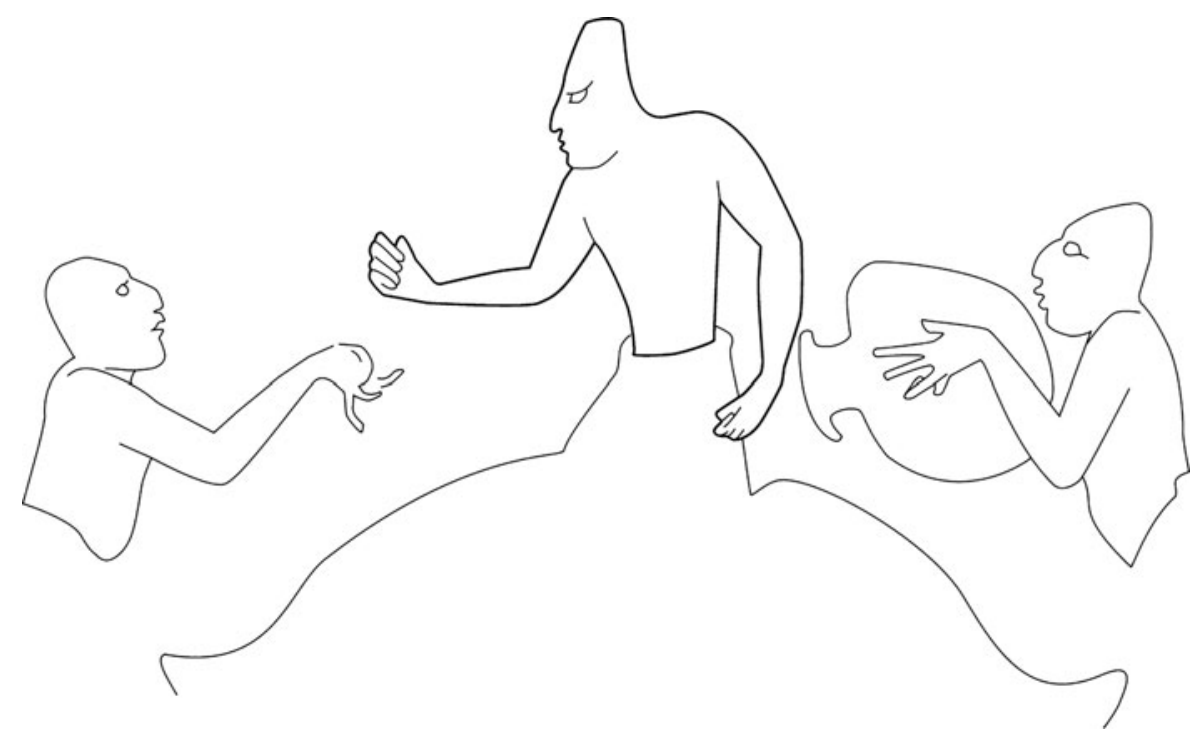

Figure 8. The Maize God demonstrating active and inactive gestures (Kerr 1999:Kerr No. K1892). Drawing by Bishop after Kerr (1999).

235 figures with 370 actively gesturing hands, down from the original 1,146 hands.

Each analysis then required its own specific parameters that warranted the removal of a few additional extraneous items. These additional exclusions are detailed in the results section when they apply.

The final corpus consisted of scenes representing both human and supernatural courts. Thus the results of the following statistical analysis represent gesture in a narrow context, focusing specifically on social interaction within courts.

\section{RESULTS: SOCIAL INTERACTIONS WITHIN A COURT CONTEXT}

Before any additional exclusions were made, a number of general observations were made about the nature of the dataset. The most common hand shapes in our data were simple, unidirectional ones such as the crossed and unilateral gestures. Segmented hand shapes were less common, with the trisected and quadrisected gestures representing less than 10 percent of the total hands recorded. In terms of accommodation, figures overwhelmingly used direct gestures when interacting with their interlocutor. Less than 25 percent of gestures were indirect, and less than 10 percent made no accommodation to the interlocutor, suggesting that it is normative for characters to adapt themselves to the people around them in a scene. Also, it is worth noting that regardless of whether or not all figures beyond the proximal position were combined into a single distal category, the results of comparing position to gesture showed the same patterns, demonstrating that the findings were robust.

In this corpus, a figure's position in a scene roughly corresponded to the social significance or status of that figure. Focal figures were typically unique individuals, such as specific gods from the Maya pantheon, named historical figures, and kings. In human palace scenes, proximal figures were typically individuals of distinguishable status or profession, such as foreign dignitaries, scribes, and warriors. These characters were occasionally given formal titles in the vessel texts, such as sajal, the equivalent of a regional governor, or ajk'uhuun , meaning "he of the holy books" (Jackson 2013). Distal figures were much less distinctive in their dress, accoutrements, and attributes, and were often classified as a general subsidiary or attendant. These classifications of the different positions are not absolute, but they do reflect the general trends observed in the placement of different types of figures.

\section{Gesture form}

Before analyzing gesture form, we excluded hands that were categorized as not readable $(n=32)$ and gestures which had too few examples to evaluate statistically $(n=1)$. Once these were removed from the analysis, 337 actively gesturing hands remained in the dataset (Table 1).

We examined the relationship between hand gesture and the proximity to the focal figure and found an inverse relationship between the complexity of hand shape and the distance to the focal figure. As figures move further away from the focal, their gestures become less complex (Figure 9). In comparison to other figures, focal figures used relatively more complex gestures like the trisected and bisected gesture, and fewer simple gestures like unilateral and crossed. In contrast, distal figures use basic gestures more often than figures in other positions, and their use of each gesture decreases as the complexity increases. Proximal figures fell between the other two positions in that they used fewer complex gestures than focal figures and fewer crossed gestures than distal figures. Overall, we found the Maya elite used segmented and multidirectional hand shapes more frequently, in comparison to the servants, attendants, and lower ranks, who used simpler hand gestures.

A test of Cramer's V was done to determine the magnitude of the relationship between the shape of a figure's hand gestures and the figure's position in a scene. Cramer's V measures the proportion of variance of a chi-square test for independence on a scale from $0-1$, and is often used in the behavioral sciences, making its application to a gesture analysis all the more appropriate (Cohen 1988; Privitera 2017). With Cramer's V, a V of 0 signals no effect, while 0.5 signals a large effect size that in the real world might be equivalent to the difference in mean height between 13 and 18 year-old girls (Cohen 1988:26-27).

With $\mathrm{X}^{2}=62.54(\mathrm{~N}=337, d f=6)$ and $\mathrm{p}<.001$, the effect size between gesture shape and figure position is 0.3 . Although this might seem low, a $\mathrm{V}$ of 0.3 suggests a medium effect size, similar 
Table 1. Count of hand gesture forms in relation to figure position.

\begin{tabular}{|c|c|c|c|c|c|c|}
\hline & Trisected & Bisected & Unilateral Open & Unilateral Closed & Crossed & Total \\
\hline Distal & 3 & 17 & 19 & 9 & 73 & 121 \\
\hline Proximal & 12 & 20 & 22 & 16 & 68 & 138 \\
\hline Focal & 18 & 26 & 16 & 10 & 8 & 78 \\
\hline Total & 33 & 63 & 57 & 35 & 149 & 337 \\
\hline
\end{tabular}

to the difference in mean height between 14 and 18 year-old girls (Cohen 1988:26). Therefore the relationship observed between gesture complexity and status has a medium-sized effect on the data. This is not surprising, given that each position contains figures exhibiting every gesture form at least once. Nonetheless, a medium-sized effect is still noteworthy.

\section{Accommodation}

For this analysis, we included hands that had unreadable gestures, but excluded figures for which accommodation could not be calculated. This meant we excluded figures where accommodation was unknown $(\mathrm{n}=2)$. To prevent accommodation from being driven by crossed gestures, which were always coded as direct, crossed gestures were also excluded from the accommodation analysis $(\mathrm{n}=$ 149). This reduced the number of hands for the accommodation analysis to 219 (Table 2).

As the data in Table 2 show, the focal figure used direct accommodation the least, while the figures furthest from the focal point used direct accommodation most often. Inversely, focal figures make no accommodation to their interlocutor more often than any other position. Individuals in the proximal position use indirect accommodation the most, quickly followed by the focal figure, and then individuals furthest away from the focal. These patterns indicate that accommodation is directly related to the distance of an individual from the focal point of a scene. Figures that have a greater distance between themselves and the focal figure accommodate more to their interlocutor, and as individuals become closer to the central figure they accommodate less (Figure 10).

To determine the validity of these observations, Cramer's V was again used to test the strength of the relationship between a figure's position in a scene and how much he accommodated his gestures to others. With $\mathrm{X}^{2}(\mathrm{~N}=219, d f=4)=23.29$ and $\mathrm{p}<.001$, the size of the effect between gesture accommodation and a figure's position is 0.23 . This indicates that the relationship observed between accommodation and position in a scene is not very strong, but that a vague pattern does exist. The observed pattern suggests that figures of higher rank make less of an effort to adapt their movements to their interlocutor, while figures of lower rank must put more effort into adapting for the people with which they interact.

\section{INTERPRETATION}

The analyses we conducted for gesture form and accommodation show similar patterns in relation to the position of a figure within

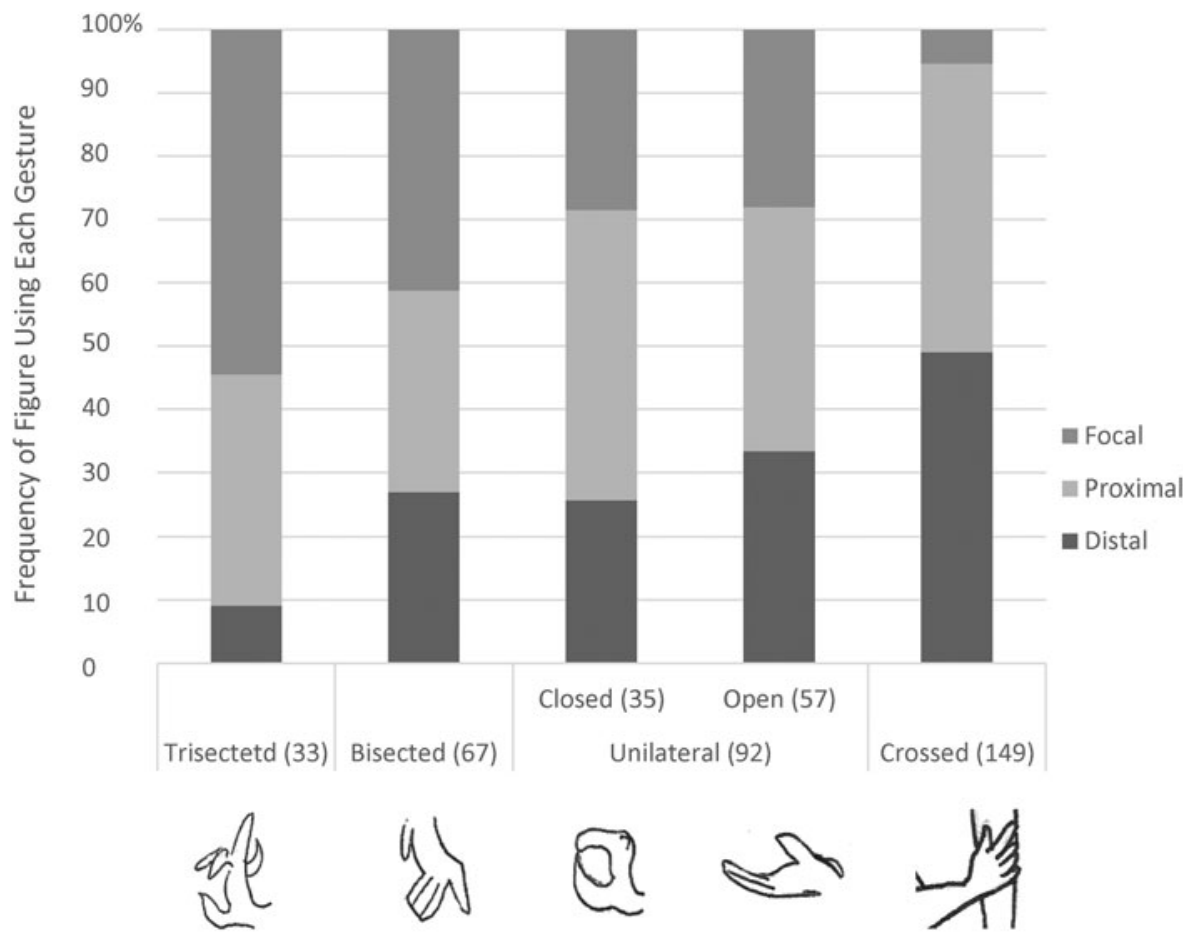

Figure 9. Frequency with which figures in each position were depicted with different types of hand gestures (n values in parentheses). Image by Bishop. 
Table 2. Count of accommodation of gesture in relation to figure position.

\begin{tabular}{lrrrr}
\hline \hline & Direct & Indirect & None & Total \\
\hline Distal & 39 & 13 & 2 & 54 \\
Proximal & 44 & 39 & 4 & 87 \\
Focal & 28 & 36 & 14 & 78 \\
Total & 111 & 88 & 20 & 219 \\
& & & & \\
\hline \hline
\end{tabular}

a scene. These similarities help to demonstrate the validity of position as a measure of social standing. Findings from the analysis of hand gestures revealed that lower-status figures predominantly used simple gestures, while high-status figures employed complex hand gestures more often. This suggests that a hierarchy of gesture existed in Maya court scenes which can be directly transferred onto a Maya system of hierarchy. The complexity of gesture is directly related to the status of a figure, and therefore the position of a figure in the scene. These findings demonstrate that gestures in a palace context are, in fact, a reflection of social importance, but they do not act as an absolute indicator of this, given that all positions have at least one instance of each gesture.

The connection between high-status personages and complex gestures is likely one manifestation of the discursive role of the elite in ancient Maya society. In the archaeological record, Maya nobility accentuated their relationship with heavenly prose by inlaying their teeth with jade and modifying incisors into a T-shape, representing the glyph for wind ( $i k^{\prime}$; Houston et al. 2006). These precious symbols alluded to sweet sounds and smells, and imbued any utterances from the elite's mouth with a holy quality. Such physical embellishments highlight the words spoken by those of high status. Speech was a privilege directly linked to Maya rulers, as the word for ruler, ajaw, translates to "shouter" or "proclaimer" (Houston et al. 2006). It follows that the physical movements of prominent personages reflect the quality of such speech, with more intricate hand gestures serving as another type of embellishment, echoing the ornateness and refinement of their speech.

The relationship between gesture shape and social status suggests a hierarchy of form related to complexity existed in Maya art. This pattern indicates first and foremost that the shape of a gesture was significant to the artist when he or she was painting a figure, either consciously or subconsciously. Furthermore, the complexity of a visual form was directly related to how prestigious or valuable it was. This concept follows a similar logic to costume in Maya art and society; those figures with the most complex and multifaceted headdress and costumes are typically the central and most important figures in a scene (see Anawalt [1981] for an extensive study of costume in Maya iconography). A study by Parmington (2003) found a similar pattern by examining the clothing of figures with official titles, such as sajal or ajaw, in Maya art. Parmington observed that the level of embellishment of a figure's costume directly corresponds to his or her title rank. Therefore, figures of the same status have equally intricate costumes, while figures of disparate status will show a difference in the sophistication of their dress and accouterments (Parmington 2003). This pattern is reflected in actual mortuary contexts, where highly intricate costumes and jewelry are mostly restricted to royal and elite burials (Chase 1992; Haviland and Moholy-Nagy 1992; Pendergast 1992). The relationship between status and level of adornment corresponds directly to the hierarchy of complexity that is also apparent in gesture. While it is not surprising that prestige is linked to more complex visual forms, it is interesting that this principle extends to gesture. At a minimum, this suggests that the Maya looked at the hands as an expressive medium to communicate information, and not simply as an idle or random decorative element.

The patterns associated with how a figure accommodates to his or her interlocutor are also compelling. The focal figure uses both indirect accommodation and no accommodation more often than distal figures, which favor direct accommodation instead. This contrast between position and accommodation marks a relationship

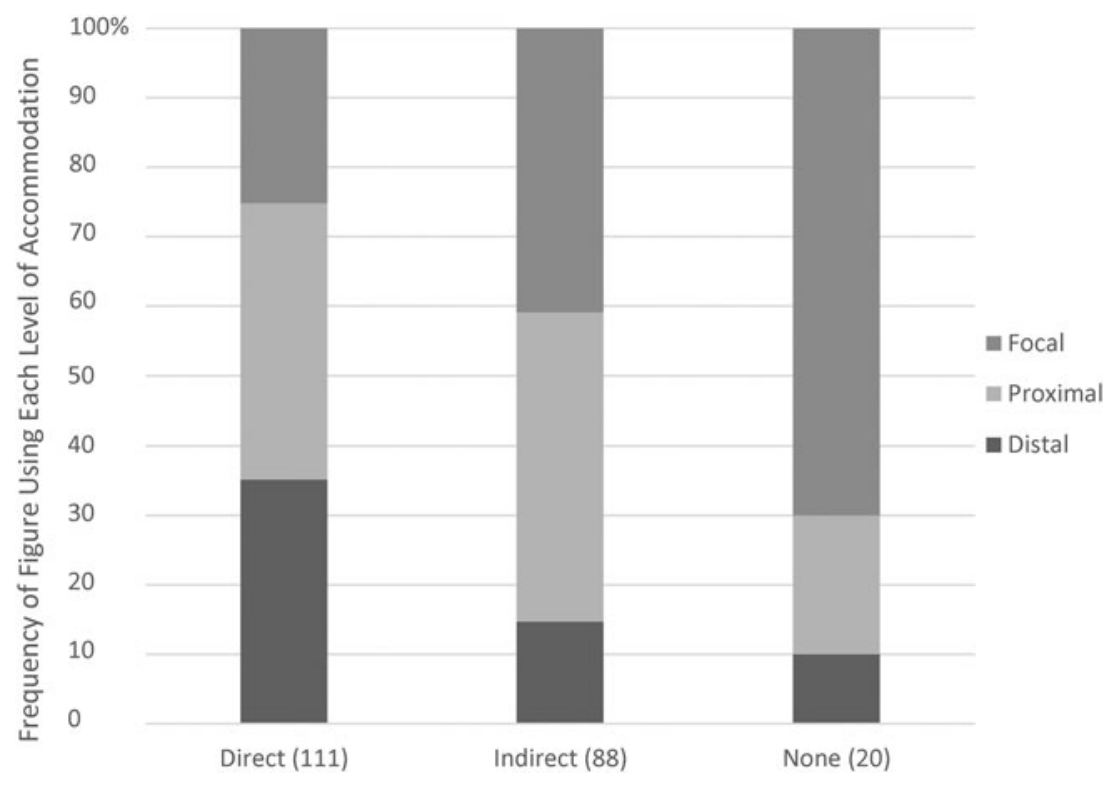

Figure 10. Frequency with which figures in each position were depicted with different levels of accommodation (n values in parentheses). Graph by Bishop 
between an individual's status and how they interact with others. Figures of lower status and significance put more effort into bending, reaching, and adapting their bodies and expressions so that they are easily visible to others. Figures of higher status, however, make this effort less frequently, and typically do not go out of their way to adjust their bodies to those around them. This suggests that a hierarchy of physical accommodation exists as well (albeit to a weaker extent), one which relates social status to compliance within Maya courts. Individuals that adjust their bodies to the needs of others are more frequently of a lower class, while those who do so less frequently are of a higher class. This may be due to the interactional access that lower class figures have to the focal figure in a scene. Individuals that are spatially closer to the king at a gathering are more visible to him than servants and low subsidiaries who, in artistic scenes, are shown further away. Therefore, these lower ranking individuals must put more effort into making their gestures noticed. In contrast, the king himself is carefully watched by all, so he need not expend great effort to make his physical expressions seen. Such a model demonstrates that how figures physically move when they interact in palace contexts can also be related to their place in the social hierarchy. As with gesture form, these patterns are not absolute, but rather a reflection of general preference and tendency.

Accommodation patterns provide insight into Maya perceptions of class interaction and how figures of various ranks were expected to communicate with others within a palace context. The finding that figures of lower status in palace scenes are the most accommodating to their interlocutors suggests that, overall, status in Maya society could be seen in the expectations of bodily comportment, and that concern for the interlocutor was expected to be of primary importance to lower class individuals in the courts. These are examples of Bourdieu's "bodily hexis," the phenomenon in which social structures are absorbed by the body and physically performed. In this case, the bodies represented on Maya ceramics inhabit and perform the class structures that govern Classic Maya society. The "bodily hexis" exhibited here may therefore give a glimpse into the habitus of the different classes of the ancient Maya.

The patterns above might seem to suggest that we should find dichotomies in representations of the Maya body. An artist expresses a figure's role in society by making the choice to use simple versus complex forms, obliging versus indifferent movements, combined with other visual cues such as clothing, jewelry, orientation, and height to make a character's significance obvious to the audience. However, our research shows gradients rather than dichotomies. The Maya world is rarely binary. Instead it is a world of conglomerates and inconsistencies that must be measured based on the sum of all parts, rather than the existence of a single feature. This is especially true in Maya iconography, where a figure cannot be defined based on the presence or absence of one element. For example, certain items of clothing and paraphernalia are associated with the ajk'uhuun, a title for expert scribes in Maya art. These identifiers include a headcloth, a stick bundle attached to or pens protruding from the headdress, and a sarong bundled at the waist (Coe and Kerr 1997). A figure with just one of these items may have scribal skills. However, the figure must possess combination of these elements to be confidently labeled an ah k'un hun. Similarly, while the Maya pantheon consists of a number of major gods with distinctive attributes, there are also supernatural figures that appear as a combination of multiple gods, or that appear with aspects of other gods (Taube 1992). Studies of the types of clothing worn by different individuals, such as Parmington's (2003) research on sajal and ajaw figures, Taube's (1992) guide to the gods of the Yucatan, and Anawalt's (1981) catalogue of Postclassic clothing worn by deities, show that no single item is exclusive to a certain title or god in Maya iconography, rather it is the accumulation of features that distinguishes individuals.

Studies of Maya iconography that use statistical analysis to measure relationships between status markers also conclude that combinations of elements are the most successful markers. For example, Kettunen's (2006) research on nasal motifs (one of the first studies to use extensive statistical methods in Maya art) examined whether, among other things, nose ornaments were a symbol of status. Kettunen found that while the wearing of nose ornaments was undoubtedly connected to figures of high status in Maya iconography, this trend was not absolute, and many examples did not fit the pattern. For these reasons, it is important to remember that a figure in Maya iconography would not have been easily interpreted by the audience using a single attribute.

Furthermore, recent research indicates that hierarchy in Maya society was more nuanced than previously realized, and consisted of a number of levels and positions that are not yet fully understood in terms of their ranking within the Maya hierarchy, or their social, religious, or political significance (Chase 1992; Inomata and Houston 2001; Jackson 2013; Rossi et al. 2015; Stuart 2013). These findings suggest that any study of social hierarchy and its indicators in Maya art will reflect numerous overlapping cultural factors that were at play during the Classic period. Given the cosmopolitan nature of these vessels, it therefore seems likely that any status or hierarchy depicted on these vessels was quite complex.

It is for this reason that a statistical approach to ancient art is useful. With so many overlapping elements that can vary, changes in the use of individual elements can be difficult to detect, especially when searching for patterns in unfamiliar or untraditional topics of study. Part of the reason certain patterns may be so difficult to detect may be because the artists themselves do not structure their depictions of these variables intentionally or consciously, but rather produce images that correspond to their own intuitions about figures with different social ranks. This would make it all the more difficult for the viewer to detect patterns thousands of years later. This study demonstrates the credibility and potential utility of applying statistical methods to studies of gesture in archaeology, as well as to studies of early art more broadly.

\section{CONCLUSIONS AND CAVEATS}

With the aid of statistical analysis, this study links social hierarchy with the portrayal of the body on Classic Maya pottery. We found that in palace scenes, the status of painted figures correlates with the types of gestures they are likely to exhibit, and the extent to which they adapt their movements to others in a scene. Individuals of higher status are depicted with more complex hand gestures and less physical accommodation towards others, while individuals of low status reflect the opposite trends, with more simple hand gestures and greater adjustments towards interactional partners. While these trends do not necessarily reflect the reality of bodily movements in ancient Maya courts, they do demonstrate cultural values and idealized interactions in formal palace settings. Furthermore, the patterns we find in hand gestures provide further evidence for a link between complexity of visual ornamentation and social standing that has been identified previously in depictions of ancient Maya clothing and jewelry. Ultimately though, all of these trends present on a gradient rather than a binary plane, and 
can be used holistically to aid in the interpretation of painted figures, but not singularly as a means to define them.

Finally, it is important to note that this entire study revolves around the depiction of gestures in a single, narrow context. The material examined here represents figures in a palace context. In narrative scenes, overlapping and multiple levels of figures made it difficult to clearly determine the position, and therefore the social significance, of a figure. This suggests that gestures in narrative scenes may not follow the same logic as those in palace scenes, and raises questions regarding the use of gesture across different artistic contexts. Because the models of status and interaction uncovered here cannot be applied to gestures in narrative scenes, it is possible that gesture use in Maya art is contextually based, and adheres to different rules or expectations based on the type of scene depicted. The purpose of depictions of gesture may, in fact, be related to the purpose of the image itself. Every image on Classic Maya vessels is made with the purpose of conveying a scene or story to the audience, and each scene or story has an underlying message or theme. In the case of court and palace scenes, it seems likely that the theme of the image is hierarchy, social structure, and proper etiquette, while narrative scenes are meant to invoke the viewers memory of a specific myth. In this way palace and narrative scenes have completely different purposes, which may explain the difference in their gesture systems. It appears, therefore, that gesture use in Maya art may relate to the purpose or message of the image being analyzed, and does not operate under an absolute system. Instead, it may change to best suit the purposes of the artist, making it a truly relative form of visual communication.

\section{RESUMEN}

El arte de los mayas del periodo clásico (250-900 d.C.) está repleto de figuras expresivas en una variedad de poses y posturas muy estilizadas. Las posturas son tan especificas que parecen tener la intención de comunicar algo, pero sus mensajes son elusivos. Investigaciones previas surgieren que existe una correlación entre el lenguaje corporal y los roles sociales en el arte maya. El presente estudio se enfoca en un tipo específico de lenguaje corporal en el arte maya clásico: los gestos de las manos, e investiga si dicho lenguaje representa y refleja elementos de la estructura social. Este análisis emplea un nuevo método de codificación para analizar los gestos en el arte antiguo que se deriva del estudio de los gestos manuales en la conversación. Dicho método implica el estudio de un medio estático a través de una perspectiva de interacción. Utilizando métodos estadísticos, evaluamos los patrones en el uso de gestos de 235 figuras que aparecen en escenas palaciegas representadas en 89 vasos mayas; los resultados indican que la forma y, en menor medida, el ángulo de los gestos están relacionados con la jerarquía social. Los datos muestran que las figuras de alto estatus son representadas frecuentemente con complicados gestos de manos, mientras que las figuras de estatus bajo suelen presentar gestos manuales más simples. Este patrón fue corroborado con el análisis estadístico Cramer's V, el cual indica que la relación entre la complejidad gestual y el estatus tiene una magnitud de asociación moderada $(\mathrm{V}=0.3)$. Además de estudiar cada figura individualmente, consideramos también la interacción entre personajes. Observamos que los personajes de alto rango parecen hacer un menor esfuerzo para ajustar sus movimientos al interlocutor, mientras que las personajes de bajo rango se esfuerzan más en adaptar sus posiciones a los personajes con los que interactuan. Esta asociación resultó más débil que la relación entre complejidad de gestos y estatus; sin embargo, vale la pena mencionarla pues presenta un efecto de 0.23 . Nuestros hallazgos demuestran que la forma especifica de representar los gestos fue significativa para los artistas que pintaban estas figuras, lo hayan hecho de manera consciente o subconsciente, y que la complejidad de una forma visual está relacionada directamente con su valor y prestigio. Así mismo, los patrones asociados con la manera en que un personaje se adapta a su interlocutor sugieren que también en el arte existía una jerarquía de adaptación de la postura física (aunque a una menor escala) que estaba relacionada con el estatus social, de acuerdo con lo que era habitual en las cortes mayas. Los resultados ofrecen nueva información sobre la forma en que los mayas representaban el lenguaje gestual en el arte, y son un ejemplo de cómo la representación figurativa refleja estructuras sociales.

\section{ACKNOWLEDGMENTS}

The guidance and insightful comments of Richard Lesure, John Papadopoulos, and Tom Garrison were instrumental in this paper, and must be acknowledged first and foremost. We are grateful to the Popol Vuh Museum in Guatemala City and the Los Angeles County Museum of Art for granting access to their collections in the early stages of this study, and to Andrea Terrón specifically for welcoming Anna Bishop into her facilities. We also thank the reviewers for their detailed and helpful comments on the manuscript. Finally, we thank the Cotsen Institute of Archaeology, the Steinmetz family, and the UCLA Latin American Institute for their support of this research.

\section{REFERENCES}

Anawalt, Patricia Rieff

1981 Indian Clothing Before Cortés: Mesoamerican Costumes from the Codices. University of Oklahoma Press Norman.

Ancona-Ha, Patricia, Jorge Perez de Lara, and Mark Van Stone

2000 Observations on Hand Gestures in Maya Art. In Maya Vase Book, Vol. 6, edited by Justin Kerr, pp. 1072-1089. Kerr Associates, New York.

Baines, John

1990 Restricted Knowledge, Hierarchy, and Decorum: Modern Perceptions and Ancient Institutions. Journal of the American Research Center in Egypt 27:1-23.

Benson, Elizabeth

1973 Gestures and Offerings. In Primera Mesa Redonda de Palenque
Part I, edited by Merle Greene Robertson, pp. 109-120. Robert Louis Stevenson School, Pebble Beach.

Boot, Erik

2003 The Human Hand in Classic Maya Hieroglyphic Writing. Electronic document, http://www.mesoweb.com/features/boot/ human_hand.pdf, accessed April 12, 2015.

Bourdieu, Pierre

1977 Outline of a Theory of Practice. Cambridge University Press, Cambridge.

1990 The Logic of Practice. Stanford University Press, Stanford.

Bremmer, Jan

1991 Walking, Standing, and Sitting in Ancient Greek Culture. In A Cultural History of Gesture: From Antiquity to the Present Day, 
edited by Jan Bremmer and Herman Roodenburg, pp. 15-35. Polity Press, Cambridge.

Bricker, Victoria Reifler

1981 The Indian Christ, the Indian King: The Historical Substrate of Maya Myth and Ritual. University of Texas Press, Austin.

Chase, Arlen F.

1992 Elites and the Changing Organization of Classic Maya Society. In Mesoamerican Elites: An Archaeological Assessment, edited by Diane Z. Chase and Arlen F. Chase, pp. 30-37. University of Oklahoma Press, Norman.

Coe, Michael D., and Justin Kerr

1978 Lords of the Underworld: Masterpieces of Classic Maya Ceramics. Princeton University Press, Princeton.

Coe, Michael D., and Justin Kerr

1997 The Art of the Maya Scribe. Thames and Hudson, London.

Cohen, Jacob

1988 Statistical Power Analysis for the Behavioral Sciences. 2nd ed. Lawrence Erlbaum Associates, Hillsdale.

Depreux, Philippe

2009 Gestures and Comportment at the Carolingian Court: Between Practice and Perception. Past and Present 4:57-59.

Goffman, Erving

1963 Behavior in Public Places. Free Press, New York.

1981 Replies and Responses. In Forms of Talk, edited by Erving Goffman, pp. 5-77. University of Pennsylvania Press, Philadelphia.

Goodwin, Charles

1981 Conversational Organization: Interaction Between Speakers and Hearers. Academic Press, New York.

1986 Gestures as a Resource for the Organization of Mutual Orientation. Semiotica 62:29-49.

Graf, Fritz

1991 Gestures and Conventions: The Gestures of Roman Actors and Orators. In A Cultural History of Gesture: From Antiquity to the Present Day, edited by Jan Bremmer and Herman Roodenburg, pp. 59-70. Polity Press, Cambridge.

Haviland, John B.

1998 Early Pointing Gestures in Zinacantan. Journal of Linguistic Anthropology 8:162-196.

Haviland, William, and Hattula Moholy-Nagy

1992 Distinguishing the High and Mighty from the Hoi Polloi at Tikal, Guatemala. In Mesoamerican Elites: An Archaeological Assessment, edited by Diane Z. Chase and Arlen F. Chase, pp. 50-60. University of Oklahoma Press, Norman.

Houston, Stephen

1998 Classic Maya Depictions of the Built Environment. In Function and Meaning in Classic Maya Architecture: A Symposium at Dumbarton Oaks, 7th and 8th October 1994, edited by Stephen Houston, pp. 333-372. Dumbarton Oaks Research Library and Collection, Washington, DC.

Houston, Stephen D., David Stuart, and Karl A. Taube

1989 Folk Classification of Classic Maya Pottery. American Anthropologist 91:720-726.

Houston, Stephen D., David Stuart, and Karl A. Taube

2006 Memory of Bones. University of Texas Press, Austin.

Houston, Stephen D., and Takeshi Inomata

2009 The Classic Maya. Cambridge University Press, Cambridge.

Inomata, Takeshi, and Stephen D. Houston

2001 Royal Courts of the Ancient Maya: Volume One Theory, Comparison and Synthesis. Westview Press, Boulder.

Jackson, Sarah E.

2009 Imagining Courtly Communities: An Exploration of Classic Maya Experiences of Status and Identity through Painted Ceramic Vessels. Ancient Mesoamerica 20:71-85.

2013 Politics of the Maya Court: Hierarchy and Change in the Late Classic Period. University of Oklahoma Press, Norman.

Just, Bryan

2012 Dancing into Dreams: Maya Vase Painting of the Ik' Kingdom. Princeton University Art Museum, Princeton.

Kendon, Adam

1988 Goffman's Approach to Face-to-Face Interaction. In Erving Goffman: Exploring the Interaction Order, edited by Paul Drew and Anthony Wootton, pp. 14-40. Polity Press, Cambridge.

2004 Gesture: Visible Action as Utterance. Cambridge University Press, Cambridge.
Kerr, Justin

1989 A Maya Vase from the Ik Site. Record of the Art Museum, Princeton University 48:32-36.

1999 The Maya Vase Database. Electronic database, http://research. mayavase.com/kerrmaya.html, accessed January 2, 2015.

Kettunen, Harri J.

2006 Nasal Motifs in Maya Iconography: A Methodological Approach to the Study of Ancient Maya Art. Ph.D. dissertation, Renvall Institute for Area and Cultural Studies, University of Helsinki, Helsinki.

Kita, Sotaro

2009 Cross-Cultural Variation of Speech-Accompanying Gesture: A Review. Language and Cognitive Processes 24:145-167.

Le Guen, Olivier, and Lorena Ildefonsa Pool Balam

2012 No Metaphorical Timeline in Gesture and Cognition Among Yucatec Mayas. Frontiers in Psychology 3:271.

Matthews, Steven

2004 Gesture, Gender, Ethnicity: The Instantiated Communities of Bronze Age Europe. Archaeological Review from Cambridge 19: $56-72$.

Mauss, Marcel

1973 Techniques of the Body. Economy and Society 2:70-88.

McAnany, Patricia Ann

1995 Living with the Ancestors: Kinship and Kingship in Ancient Maya Society. University of Texas Press, Austin.

McNiven, Timothy John

1982 Gestures in Attic Vase Painting: Use and Meaning, 550-450 BC $\mathrm{Ph} . D$. dissertation, Department of Art History, University of Michigan, Ann Arbor.

2007 Behaving Like a Child: Immature Gestures in Athenian Vase Painting. In Constructions of Childhood in Ancient Greece and Italy, edited by Ada Cohen and Jeremy B. Rutter, pp. 85-99. American School of Classical Studies, Athens.

Miller, Virginia E.

1981 Pose and Gesture in Classic Maya Monumental Sculpture. Ph.D. dissertation, Department of Art History, University of Texas at Austin, Austin.

1983 A Reexamination of Maya Gestures of Submission. Journal of Latin American Lore 9:17-38.

Olko, Justyna

2014 Body Language in the Preconquest and Colonial Nahua World. Ethnohistory 61:149-179.

Palka, Joel

2002 Left/Right Symbolism and the Body in Ancient Maya Iconography and Culture. Latin American Antiquity 13:419-443.

2014 Maya Pilgrimage to Ritual Landscapes: Insights from Archaeology, History, and Ethnography. University of New Mexico Press, Albuquerque.

Parmington, Alexander

2003 Classic Maya Status and the Subsidiary "Office" of Sajal: A Comparative Study of Status as Represented in Costume and Composition in the Iconography of Monuments. Mexicon 25:46-53.

Pendergast, David

1992 Noblesse Oblige: The Elites of Altun Ha and Lamanai, Belize. In Mesoamerican Elites: An Archaeological Assessment, edited by Diane Z. Chase and Arlen F. Chase, pp. 60-92. University of Oklahoma Press, Norman.

Privitera, Gregory J.

2017 Research Methods for the Behavioral Sciences. 2nd ed. Sage, Los Angeles.

Quinn, Naomi

2008 Metaphoric Gestures and Cultural Analysis. In Metaphor and Gesture, edited by Alan Cienki and Cornelia Müller, pp. 253-258. John Benjamins Publishing, Philadelphia.

Reents-Budet, Dorie

1994 Painting the Maya Universe: Royal Ceramics of the Classic Period. Duke University Press, Durham.

1998 Elite Maya Pottery and Artisans as Social Indicators. Archaeological Papers of the American Anthropological Association 8:71-89.

2000 Classic Maya Concepts of the Royal Court: An Analysis of Renderings on Pictorial Ceramics. In Royal Courts of the Ancient Maya, Volume One: Theory, Comparison, and Synthesis, edited by Takeshi Inomata and Stephen D. Houston, pp. 195-236. Westview Press, Boulder. 
Reents-Budet, Dorie, Sylviane Boucher Le Landais, Yoly Palomo Carrillo,

M. James Blackman, and Ronald L. Bishop

2010 Codex-Style Ceramics: New Data Concerning Patterns of Production and Distribution. Paper presented at the XXIV Simposio de Investigaciones Arqueológicas en Guatamala, Guatemala City.

Robicsek, Francis, and Donald Hales

1981 The Maya Book of the Dead: The Ceramic Codex; The Corpus of Codex Style Ceramics of the Late Classic Period. University of Virginia Art Museum, Charlottesville.

Schmitt, Jean-Claude

1991 The Rationale of Gestures in the West: Third to Thirteenth Centuries. In A Cultural History of Gesture: From Antiquity to the Present Day, edited by Jan Bremmer and Herman Roodenburg, pp. 59-70. Polity Press, Cambridge.

Strecker, Matthias

2013 Hand Images in Maya Caves. Proceedings of American Indian Rock Art 40:507-529.

Stuart, David

1989 Hieroglyphs on Maya Vessels. In The Maya Vase Book, Vol. 1, edited by Justin Kerr, pp. 149-160. Kerr Associates, New York.

2013 Early Thoughts on the Sajal Title. Electronic document, https:// decipherment.wordpress.com/2013/11/19/early-thoughts-on-the-sajaltitle, accessed January 25, 2016.

Taschek, Jennifer T., and Joseph W. Ball

1992 Lord Smoke-Squirrel's Cacao Cup: The Archaeological Context and Sociohistorical Significance of the Buenavista "Jauncy Vase." In The Maya Vase Book, Vol. 3, edited by Justin Kerr, pp. 490-497. Kerr Associates, New York.

Taube, Karl A.

1992 The Major Gods of Ancient Yucatan. Dumbarton Oaks Research Library and Collection, Washington, DC.

Tedlock, Barbara

1992 Time and the Highland Maya. University of New Mexico Press, Albuquerque.

Throop, Jason, and Keith M. Murphy

2002 Bourdieu and Phenomenology: A Critical Assessment. Anthropological Theory 2:185-207.

Todaro, Dale

1985 The Meaning of the Term Mudrā and a Historical Outline of "Hand Gesture." Journal of Esoteric Buddhism 151:54-71.

Troike, Nancy P.

1982 The Interpretation of Postures and Gestures in the Mixtec Codices. In The Art and Iconography of Late Post-Classic Central Mexico: A Conference at Dumbarton Oaks, October 22nd and 23rd, 1977, edited by Elizabeth Hill Boone, pp. 175-206. Dumbarton Oaks, Trustees for Harvard University, Washington, DC.

Zender, Marc

2004 Glyphs for "Handspan" and "Strike" in Classic Maya Ballgame Texts 1. The PARI Journal-Online Publications 4:1-9. 